\title{
Students' Verbal and Nonverbal Communication Patterns:
}

\author{
A Gender Perspective
}

\author{
Dini Hadiani*, Emma Dwi Ariyani \\ Design Engineering Department \\ Politeknik Manufaktur Bandung \\ Bandung, Indonesia \\ *dinibhs@polman-bandung.ac.id, emma@polman-bandung.ac.id
}

\begin{abstract}
Interpersonal communication consists of verbal components and nonverbal symbols. It is believed that gender differences exist for both communication components. This research attempts to obtain a description of the students' verbal and nonverbal communication patterns concerning gender and to find out how male and female students interact with each other. Employing DeVito's model of communication patterns, this study was conducted through a descriptive method. The results show that male students tend to use oral verbal communication instead of nonverbal communication. It indicates that male students prefer to interact with their friends directly in the face to face interaction. While female students tend to use both verbal and nonverbal communication, but more nonverbal communication compared to male students. It can be said that female students prefer to use various patterns to communicate, and they are able to share their opinions in the media. Concerning the difference in communication patterns performed by male and female students that influence their communication skills, it is imperative that teachers should formulate the appropriate teaching methods to improve the students' communication skills.
\end{abstract}

Keywords-communication patterns, gender, nonverbal communication, verbal communication

\section{INTRODUCTION}

In the academic environment, students should have the ability to interact with the teacher, other students, and other academic community members. It is believed that the quality of the teacher and student relationship influences academic achievement and student behaviour [1]. The relation between students and other students relies on verbal and nonverbal communication. Students should produce words correctly during the interaction, such as delivering ideas in a discussion, having a short talk, gossiping, and sharing jokes. Nonverbal communication, on the other hand, includes the ability to listen actively. Students should be able to listen carefully to their friends to show empathy. Besides, nonverbal communication also includes body language. This activity becomes an essential part of communication since more than $50 \%$ of communication is performed through nonverbal symbols, such as eye contact, smile, facial expression, and gesture. Therefore, verbal and nonverbal communication skills are two aspects that need to be improved by students to support their academic lives.

Many researchers have studied verbal and non-verbal communication in the learning environment [2-5]. The results of the study show that nonverbal communication can be an essential source of motivation for students' learning [2] as nonverbal communication has a lot of benefits in communication [3]. Verbal and nonverbal communication should be used in learning materials to significantly affect the students' achievement [4] since the teacher's ability to apply verbal and nonverbal communication can enhance the quality of learning [5].

Based on the elaboration of previous research on verbal and nonverbal communication in the learning environment, it was found that verbal and nonverbal communication is essential for developing students' academic achievement. However, little has studied the students' insight into verbal and nonverbal communication patterns based on gender. It is believed that gender differences exist for both communication components. Women are reported to use more expressive and involve nonverbal behaviours than men, and men are louder and more interactive [6]. It is also stated that both men and women communicate in particular ways, associated with their gender [7]. Another study also found that male and female students picked different dominance in communication concerning their interpersonal skills [8]. Taken these phenomena into consideration, it is, therefore, necessary to explore the students' verbal and nonverbal communication based on gender perspective to find out how male and female students interact with each other. It attempts to study the elements of verbal communication consisting of the use of words orally and in writing. The elements of nonverbal communication covering body language, facial expression, and gesture during the interaction between male and female students are also identified. Having excellent verbal and nonverbal communication will make students establish communication and socialize with their friends. This condition will influence their communication skills, and it will eventually lead them to 
be successful in their studies. The results are supposed to contribute to the study of verbal and nonverbal communication in terms of gender. Furthermore, the information in this study can be a guidance for future researches on the same interest.

\section{THEORETICAL FRAMEWORK}

\section{A. Communication Skills}

Communication is an activity to exchange information. Communication may involve the exchange of ideas, opinions, and information with a specific objective. Information can be exchanged through oral communication and also symbols. Communication can be defined as a process to share and give meaning through symbolic interactions [9]. In the process of communication, we are not only communicating with each other with verbal, but also nonverbal communication. To share meaning, we use verbal communication through words, and we also need nonverbal behaviours (gestures, postures, eye contact, facial expressions). It means that the words we speak and the body movement that we make are conveyed through verbal components and nonverbal symbols.

Concerning the communication pattern, this term is commonly referred to as a communication model, which consists of various interconnected components best used for community educational purposes [10]. Communication pattern includes the Primary Communication Pattern in which communicators make a message delivery process to communicants through verbal and non-verbal. It also includes a Secondary Communication Pattern where a message delivery process is made by communicators to communicants using tools. A Linear Communication Pattern in which its literal meaning moves from one point to another in a straight line, and a Circular Communication Pattern where feedback is given to the communicator by communicants are also another type of communication pattern [10]. Since this study concerns the verbal and nonverbal communication patterns of male and female students, so it focuses on the primary communication pattern.

Communication skills may refer to the ability to convey a message and the feeling behind it for the desired effect. Thus, it includes various aspects of conveying - verbal, nonverbal, and interpersonal [11]. It can be said that someone who has excellent communication skills will be good at applying verbal and nonverbal communication during the interaction.

\section{B. Verbal Communication Skills}

Verbal communication is a type of communication using words that could be conveyed orally, such as face-to-face conversations, telephone calls, interviews, and presentations, or in written forms such as emails, chat messages, and reports. Verbal communication uses words and writings. In oral communication, the form of verbal messages depends on the form of vocabulary, and it should consider two things; the information can be observed by others, and it should raise meaning for others. The results of verbal communication activities are verbal messages [12].
Verbal communication is used to inform, either to inform our needs or to impart knowledge. The critical components in verbal communication are: (1) Messages are packaged, (2) meanings are in people, (3) meanings are denotative and connotative, (4) messages vary in abstraction, (5) messages vary in politeness, (6) messages can deceive, (7) messages can criticize, and praise, (8) messages vary in assertiveness, (9) messages can confirm and disconfirm, and (10) messages vary in cultural sensitivity [13].

There are several advantages of verbal communication. It is fast, and it is easy to understand [13]. Verbal communication can be expressed through oral and written, and it generates a quick response. Verbal communication can occur in a formal and informal situation, where formal verbal communication should pay attention to a structured format using defined rules $\&$ guidelines, whereas informal communication does not precisely follow the structured format of rules $\&$ guidelines.

\section{Nonverbal Communication Skills}

Nonverbal communication can be defined as a type of communication without words. It uses body movement, gesture, and facial expression. The important part of nonverbal communication is that the message is received by one or more other people. We have to be very careful as the nonverbal symbols and the expressions used can impact the other person. Nonverbal communication works very well with verbal communication at times. Verbal and nonverbal messages interact with each other in six primary ways: to accent or to emphasize some parts of the verbal messages, to complement or to add meaning, to contradict the meaning, especially when someone is lying, to control the flow of verbal messages, to repeat, and to substitute the verbal messages [13].

There are several types of nonverbal communication. They are Kinesics deals with the use of body movement communication (gestures, eye contact, facial expressions, haptics /touch, posture; Proxemics, which is the use of space to communicate; and Para-Language or vocalists referring to the vocal but non-verbalized including volume, pitch, vocal rate $[13,14]$

\section{Gender and Communication Skills}

Several factors may influence people's communication styles, which include gender differences. In general, men and women speak differently because those ways are associated with their gender [7]. Based on her proposition, the male communication pattern is considered "report" type talk, in which males are more likely to use conversation as a means of establishing status and power. In contrast, female communication pattern is considered a "rapport" type talk in which they tend to use conversation to build connections and create intimacy. Therefore, the conversation of the male is more competitive, while the conversation of the female is more cooperative than that of males. Men pay attention to power and status, while women tend to emphasize feelings and building relationships. 
Men are believed to be more indirect when they express weakness, reveal a problem, or admit an error. Women, on the other hand, are believed to be politer and expressive in showing empathy, sympathy, and supportiveness more than men [13]. These gender differences are reported to occur for several reasons; inherited biological factors, socialization on how men and women are raised, and inequalities in social power [15].

\section{METHODOLOGY}

The descriptive method is employed to describe a state at the time of research. This research uses a set of questionnaires to view the verbal and nonverbal communication of students, both male and female.

\section{A. Participants}

The participant of the research is the students of one state vocational higher education in Bandung, Indonesia. The purposive sampling is used to select the subject that complies with the best position to support the required information. The subjects of this study are students of grades I, II, and III, as many as 96 students, consisting of 66 males and 30 females in the range of 18 to 21 years old. The description of the subjects can be seen in Table 1 below.

TABLE I. DESCRIPTION OF SUBJECT BASED ON GENDER

\begin{tabular}{|l|l|l|l|}
\hline \multirow{2}{*}{ Number } & \multicolumn{3}{|c|}{ Description } \\
\cline { 2 - 4 } & Gender & Quantity & Percentage \\
\hline 1 & Male & 66 & 69 \\
\hline 2 & Female & 30 & 31 \\
\hline Total & 96 & 100 \\
\hline
\end{tabular}

\section{B. Data Collection}

The questionnaires were developed based on the criteria of effective verbal and nonverbal communication adapted from DeVito [13], which consists of 20 statements to measure the students' verbal communication in terms of the use of words orally and in writing, and nonverbal communication in terms of body language, facial expression, and gesture. Example items used in this study are: "I can produce words correctly" and "I use gesture to emphasize what I am saying". Subjects are asked to rate the degree concerning verbal and nonverbal behaviour ranging from never (1) up to always (4). The completed questionnaire was then pilot tested among students who were not the participants of this study. It can be stated that the instrument is valid and reliable. The data analysis technique uses the mean and percentage value of the total score on each category of verbal and nonverbal communication. The data obtained from the students' verbal and nonverbal communication were then matched with the theory of gender communication

\section{RESULTS AND DISCUSSION}

This section attempts to describe the verbal and nonverbal communication based on gender perspective in vocational higher education students and to elaborate on how male and female students interact with each other.
Both male and female students shared the same interest in the frequency of using various modes of communication. It can be seen in Table 2 below.

TABLE II. THE FREQUENCY OF USING THE VARIOUS MODES OF COMMUNICATION

\begin{tabular}{|l|l|l|c|c|c|}
\hline \multirow{3}{*}{ Students } & \multicolumn{5}{|c|}{ Description } \\
\cline { 2 - 6 } & $\begin{array}{c}\text { Face to } \\
\text { face (\%) }\end{array}$ & $\begin{array}{c}\text { Phone } \\
\text { Call (\%) }\end{array}$ & $\begin{array}{c}\text { Text } \\
\text { Messages } \\
\text { /Chat } \\
(\%)\end{array}$ & $\begin{array}{c}\text { Social } \\
\text { Network } \\
(\%)\end{array}$ & $\begin{array}{c}\text { Email } \\
(\%)\end{array}$ \\
\hline Male & 80 & 60 & 73 & 63 & 45 \\
\hline Female & 87.5 & 67.5 & 81 & 65 & 54 \\
\hline
\end{tabular}

Table II shows that both male and female students prefer to use a similar frequency of using modes of communication. The most frequent modes of communication used is face to face ( $80 \%$ and $87.5 \%$ ), and it is followed by using text message/chat (73\% and $81 \%)$, using phone call $(60 \%$ and $67.5 \%)$, using social network (63\% and 65\%), and using email $(45 \%$ and $54 \%$ ). It indicates that both male and female students prefer to use face to face communication to interact with their friends. They frequently use text messages or chat and social networks, but they rarely use email to interact.

Concerning the verbal communication pattern, male students tend to rate higher to female students. It can be seen from Table 3 below.

TABLE III. STUDENTS' RATE OF VERBAL COMMUNICATION

\begin{tabular}{|c|c|c|}
\hline \multirow{2}{*}{ Verbal Communication } & \multicolumn{2}{|c|}{ Description } \\
\hline & Male & Female \\
\hline produce words correctly & 3.2 & 3.3 \\
\hline understand what people say & 3.3 & 3.2 \\
\hline speak objectively & 3.4 & 3.2 \\
\hline speak directly & 3.2 & 3.0 \\
\hline criticize people & 3.2 & 3.1 \\
\hline speak politely & 3.1 & 3.2 \\
\hline tell the truth & 3.4 & 3.4 \\
\hline use the words literally & 3.3 & 3.1 \\
\hline praise people & 3.2 & 3.2 \\
\hline speak clearly & 3.1 & 3.1 \\
\hline Average score & 3.24 & 3.18 \\
\hline
\end{tabular}

Based on data in table 3 about the students' rate of verbal communication, it shows that male students share a slightly higher rate (3.24) compared to female students (3.18). It can be said that male students are more likely to use verbal communication during their interactions. They show a willingness to create two-way communication with mutual needs and comfortable communication. Sometimes they were not aware of the importance of using the correct words. They cared much about being heard, especially when they shared jokes. It indicates that male students used verbal communication to interact with their friends, both males, and females to show that they have something to be talked about, whether it is essential or not. This situation could be influenced by the way the male students were raised to show that they are superior in the community. This finding is in line 
with the theory proposed by Tannen [7], stating that males can make a connection and to establish status and power.

Furthermore, male students tend to be louder concerning what they believe is right. They feel more comfortable communicating the ideas or opinions verbally as they think the message can be delivered more clearly through words. They also try to speak objectively and directly, especially to tell the truth. It indicates that male students are likely to be loud in saying what they think is right, but it does not mean that they are talkative. They would speak when they assumed they should. This phenomenon is supported by Briton and Hall [6], who states that male tend to be louder compared to female.

In terms of being indirect, it can be said that male students sometimes speak the words indirectly if they are in a problematic situation and to show politeness. They would try to find a way on how to communicate their problems differently, so as not to make them get embarrassed. It is in line with DeVito [13], who said that men are believed to be more indirect when they express weakness, reveal a problem, or admit an error.

In contrast, female students tend to use verbal communication in some particular situations, mainly formal situations where they are demanded to produce formal utterances. They prefer to use verbal communication on the media, such as a personal blog. They assume that they have more freedom to say their ideas or opinion in written form since sometimes they are ashamed to talk about a particular issue in the face to face communication. It indicates that female students prefer to use verbal communication regarding the situation. It may happen due to the female students' ability to select the appropriate communication patterns to be used during the interaction.

Female students are also more likely to be indirect, especially when they try to criticize their friends to show politeness and to build trust and intimacy. It might be influenced by the social belief and culture that women should be polite and able to show empathy by 'saving face' the person they are trying to criticize. This idea is supported by DeVito [13], stating that women are believed to be politer and expressive in showing empathy, sympathy, and supportiveness more than men.

Concerning the nonverbal communication pattern, it was found that female students prefer to use more body movements during their interactions. Table 4 shows the description of the nonverbal communication between male and female students.

TABLE IV. StUdENTS'RATE OF NONVERBAL COMMUNICATION

\begin{tabular}{|l|l|l|}
\hline \multirow{2}{*}{ Nonverbal Communication } & \multicolumn{2}{c|}{ Description } \\
\cline { 2 - 3 } & Male & Female \\
\hline use body language, facial expression, and gesture & 3.2 & 3.4 \\
\hline make eye contact with others while talking & 3.3 & 3.5 \\
\hline use gestures to emphasize the meaning & 3.1 & 3.4 \\
\hline interrupt others & 3.2 & 3.1 \\
\hline laugh during interaction & 3.2 & 3.3 \\
\hline smile at others & 3.1 & 3.3 \\
\hline
\end{tabular}

Table IV. Cont.

\begin{tabular}{|l|l|l|}
\hline \multirow{2}{*}{\multicolumn{1}{|c|}{ Nonverbal Communication }} & \multicolumn{2}{c|}{ Description } \\
\cline { 2 - 3 } & \multicolumn{1}{|c|}{ Male } & Female \\
\hline pay attention to other's body language & 3.2 & 3.3 \\
\hline use an expressive voice & 3.1 & 3.4 \\
\hline touch the person talking to & 3.0 & 3.3 \\
\hline interact at close distances & 3.2 & 3.3 \\
\hline Average score & $\mathbf{3 . 1 6}$ & $\mathbf{3 . 3 3}$ \\
\hline
\end{tabular}

Table 4 shows that female students (3.33) are likely to use more nonverbal communication than male students (3.16). They prefer to apply several types of nonverbal communication, such as smile, hand gesture, facial expression, and touch. They assume that using both verbal and nonverbal communication can make the interaction more relax and pleasant. The use of nonverbal communication can create more intimate relationships with others since the use of haptics or touch, for example, usually is for showing caring and love. All people cannot perform it. It will be used only in some specific circumstances where two or more people are in close relationships. It is similar to the use of space. People will tend to speak in a friendly manner, and no distance from their close friends when talking about personal issues. These nonverbal communication types are mostly used to express feelings or emotions, so other people will understand what we say more clearly. It can be said that female students tend to use nonverbal communication to build a connection with their communication partners. This finding is in line with Tannen [7], who states that females can make a connection and to create intimacy during communication.

Female students also tend to be a good listener. They can listen to their friends' stories or problems, and they are usually patient to wait for their turn to speak. Female students are assumed to be more expressive and good listeners as it is stated by Briton and Hall [6], that women were believed to be more concerned with interpersonal relationships and the affiliate needs of others. It is contradictory to male students who sometimes intrude on another person's turn to speak up his mind. This phenomenon is in line with Tannen [7], stating that males tend to use conversation to establish status and power.

Furthermore, female students prefer to interact with their friends, especially female friends, at a close distance to show that they have trust with each other. They usually talk about a personal issue, such as family, boyfriends, hobbies, and interests. This action mainly indicates that among female students exist relationship that allows them to use more nonverbal communication. This finding is supported by Briton and Hall [6], who argued that women are believed to have more considerable skill and involvement in nonverbal communication.

In contrast, male students tend to talk more since they prefer to say what they have in mind. It is assumed that for male students, nonverbal communication dealing with showing emotion is unimportant, so sometimes they neglect using it during the interaction. It can be said that male students use nonverbal communication if it is needed to show empathy or 
appreciation. It is supported by Briton and Hall [6] who state that men may see nonverbal communication of emotion as relatively unimportant

Referring to the objective of this study which is to get a description of the students' verbal and nonverbal communication patterns based on a gender perspective, it was found that male and female students use both verbal and nonverbal communication patterns during their interaction with different preferences. Male students prefer verbal communication, whereas, female students tend to use more nonverbal communication compared to males. The results of this study can be used by teachers to continue developing students' verbal and nonverbal communication skills formally and informally. It is expected that by providing guidance, several engaging communication activities, and various teaching and learning methods may improve the students' communication skills.

\section{CONCLUSION}

The study has revealed the verbal and nonverbal communication patterns of vocational higher education students. The findings show that male students tend to use verbal communication more than females. It indicates that male students prefer to interact in the face to face communication with their friends. It can be said that male students have a more dominant ability to position themselves to their communication partners. In contrast, female students tend to use more nonverbal communication compared to those of males. It indicates that female students prefer to be more expressive and comfortable interacting with their friends by using several types of nonverbal communication. The results of the study suggest that appropriate mechanisms should be formulated to enhance the students' verbal and nonverbal communication. It could be performed by providing several communication activities to encourage the students to develop their verbal and nonverbal communication that will primarily improve the students' communication skills. Having this information can enable teachers to choose and apply the appropriate methods of teaching and learning to support the development of students' verbal and nonverbal communication. Since this study mainly concerns a gender perspective, further research can identify the students' verbal and nonverbal communication in terms of culture, age variation, educational background, and other indicators.

\section{ACKNOWLEDGMENT}

The researchers would like to thank Politeknik Manufaktur Bandung for the support so that this paper can be accomplished.

\section{REFERENCES}

[1] Z. Asrar, N. Tariq and H. Rashid, "The impact of communication between teachers and students: a case study of the faculty of management sciences, University of Karachi, Pakistan," European Scientific Journal, vol. 14, pp. 32-39, 2018.

[2] C.P. Zeki, "The importance of nonverbal communication in classroom management," Procedia Social and Behavioral Sciences, vol. 1, pp. 1443-1449, 2009

[3] B. Muammar and S. Nur, "Intercultural nonverbal communication strategies in Indonesian and Thailand students' interaction," ELITE: English literature journal, vol. 2, pp. 1-15, 2015.

[4] S. Sutiyatno, "The effect of teacher's verbal communication and nonverbal communication on students' English achievement," Journal of language teaching and research, vol. 9, pp. 430-437, 2018.

[5] A. Wahyuni, " The power of verbal and nonverbal communication in learning," Advances in Social Science, Education and Humanities Research, vol. 125, pp. 80-84, 2017.

[6] N.J. Briton and J.A. Hall, "Beliefs about female and male nonverbal communication," Sex Roles, vol. 32, pp. 79-90, 1995.

[7] D. Tannen, You Just Don't Understand: Women and Men in Conversation. New York: Ballantine Books, 1991.

[8] E.D. Ariyani and D. Hadiani, "Gender differences in students' interpersonal communication," Responsible Education, Learning and Teaching in Emerging Economies, vol. 1, pp. 67-74, 2019.

[9] W.J. Seiler and M.L. Beall, Communication: making connections. 6th Edition, Pearson, 2005.

[10] J.A. DeVito, Human communication: the basic course. Longman Public Group, 1997.

[11] S. Atre, S. Jain and V. Sharma, "Impact of communication skills on professional effectiveness at the top level of hierarchy," Global Journal of Management and Business Studies, vol. 3, pp. 751-756, 2013.

[12] W. Wiryanto, Pengantar Ilmu Komunikasi. Jakarta: Gramedia Wiasarana, 2005.

[13] J.A. DeVito, The interpersonal communication. America: Pearson education, 2017

[14] T. Novinger, Intercultural Communication: A Practical Guide, First Edition. USA: University of Texas Press, 2001.

[15] J. Holmes, Women, men and politenes. New York, NY: Longman, 1995. 